\section{Gingival recession: part 2. Surgical management using pedicle grafts}

\author{
M. Patel, ${ }^{1}$ P. J. Nixon ${ }^{2}$ and M. F. W.-Y. Chan ${ }^{3}$ \\ VERIFIABLE CPD PAPER
}

IN BRIEF

- Gingival recession can be corrected using pedicle grafts but careful case selection is essential for complete root coverage.

- To ensure success of periodontal plastic surgery several patient and tooth related factors need to be assessed before surgery.

- Pedicle grafts are not suitable in cases with thin gingival biotype and in areas where there is a lack of keratinised tissue.

This paper is the second in a three part series looking at the aetiology and management of gingival recession. Part one discussed the aetiology and non-surgical management and this part aims to discuss the use of pedicle soft tissue grafts in the treatment of gingival recession. This article also considers the factors affecting the outcome of surgical procedures used to treat localised recession defects. The third paper in this series will consider the use of free soft tissue grafts and guided tissue regeneration.

\section{INTRODUCTION}

Gingival recession is defined as the apical displacement of the gingival margin from the Cemento-Enamel Junction (CEJ). ${ }^{1}$ The patient's main complaint often relates to poor aesthetics and occasionally it is related to sensitivity. Part 1 in this series discussed the aetiology of gingival recession and the non-surgical management. This paper aims to introduce some of the surgical options available to correct localised recession defects.

\section{PERIODONTAL PLASTIC SURGERY}

Periodontal plastic surgery describes any surgical procedures involving the mucogingival tissues. It includes surgery which attempts to increase the width of keratinised tissue around a tooth and cover any exposed root surface associated with a recession defect. The main indications for surgical intervention to correct recession defects include the need to improve localised soft tissue aesthetics, reduce hypersensitivity, improve plaque control and prevent further progression of recession defect. $^{2}$

\footnotetext{
"Specialist Registrar in Restorative Dentistry,

${ }^{2,3}$ Consultants in Restorative Dentistry, Department of Restorative Dentistry, Leeds Dental Institute, Clarendon Way, Leeds, LS2 9LU

${ }^{*}$ Correspondence to: Dr Mital Pate

Email:mitalpatel@nhs.net
}

\section{Refereed Paper}

Accepted 21 July 2011

DOI: 10.1038/sj.bdj.2011.821

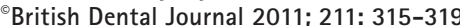

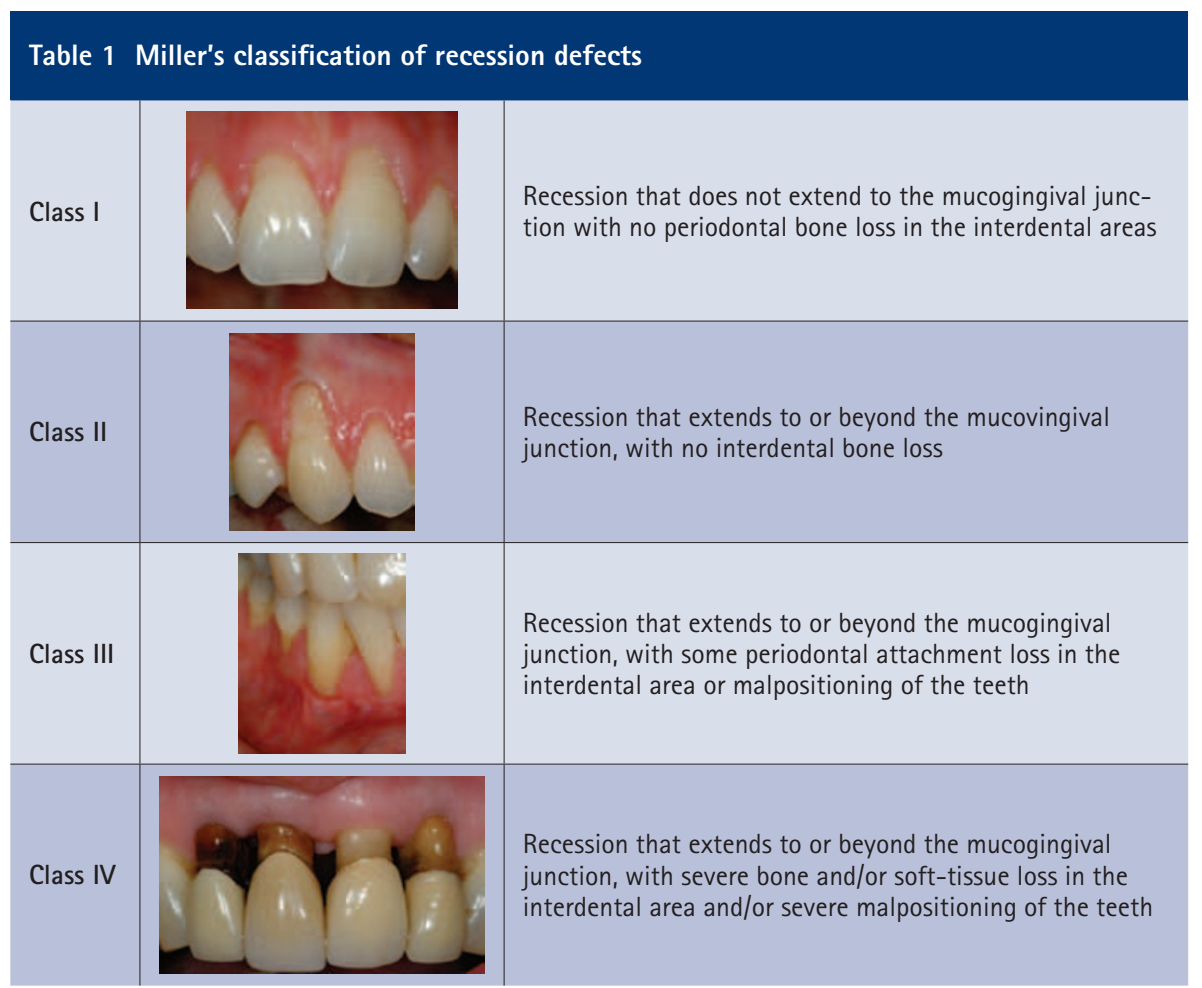

\section{CLASSIFICATION OF GINGIVAL RECESSION}

Miller $^{3}$ has classified gingival recession into four categories (Table 1). These categories can be used to assess the recession defect present and predict the possible outcome of any periodontal plastic surgery procedure which would aim to cover the recession defect and restore aesthetics. Defects classified as Miller's Class I and II can result in full coverage of the recession defect whereas class III would only provide partial coverage to the level of the interdental bone. Class IV defects are unlikely to provide any root coverage as a result of surgical intervention and therefore any periodontal plastic surgery should be avoided. This is commonly seen in patients who have developed recession due to chronic periodontal disease.

\section{FACTORS AFFECTING OUTCOME OF PERIODONTAL PLASTIC SURGERY}

There are several factors that can affect the outcome of any periodontal plastic surgery procedures. These are listed below and should be assessed and corrected where possible before surgery as part of the pre-surgical preparation or during surgery in order to improve the overall success of the procedure: 
a) Condition of root surface presence of calculus, caries, contaminated cementum or restorations on root surface

Any filling material or caries on the root surface should be removed before surgery and the root surface should be prepared by scaling to remove any residual calculus and contaminated cementum. Removal of all endotoxins, bacteria and other antigens found in contaminated cementum is essential to leave the root surface biologically compatible with healthy periodontal tissues. Lindhe and Nyman ${ }^{4}$ and Lindhe et al. ${ }^{5}$ have highlighted that thorough debridement of the root surface is essential for a successful outcome of periodontal plastic surgery attempting to provide root coverage over a recession defect. Some authors have suggested the use of citric acid to treat the root surface before the surgical procedure. The aim of this treatment is to remove the smear layer on the root surface to allow connective tissue attachment to the root surface. ${ }^{6,7}$ Others have suggested the use of tetracycline hydrochloride to help promote the healing response post surgery however, clinical studies have failed to show any improvements in outcome when using such agents. ${ }^{8}$

\section{b) Prominent frenal attachments}

Prominent frenal attachment can contribute to the cause of gingival recession. Before or as part of any periodontal plastic surgery it is worth considering carrying out a frenectomy to relieve any tension on the gingival tissues from a prominent frenum which may otherwise result in failure of the surgical procedure.

\section{c) Depth of vestibule}

Patients with shallow vestibule depth should not be considered for pedicle grafts as this can result in further decrease in vestibule depth. Alternative surgical procedures should be considered for these patients.

\section{d) Tissue type}

Patients with thin gingival biotype are likely to have a poorer outcome than those with thick gingival biotype. When considering periodontal plastic surgery it is important to assess the periodontal tissues carefully to see if the gingival tissues require a surgical procedure such as a connective tissue graft that will thicken the tissue while also correcting the recession defect. The amount of keratinised tissue available adjacent to the recession defect should also be assessed when considering rotational or coronally advanced pedicle graft. ${ }^{8}$

\section{e) Size of the recession defect and graft material}

The graft material harvested from the donor site should be large enough to cover the whole recession defect and extend beyond it in order to get adequate blood supply from the soft tissue surrounding the recession defect. As the root surface does not contribute any blood supply to the graft material, recession defects which are narrow result in a better outcome than wide recession defects as the overlap between graft material and recipient soft tissue bed will be greater. The graft should also be of an adequate thickness to prevent necrosis. ${ }^{2}$ The height of the recession defect is not as critical as the width of the defect but will influence the choice of surgical procedure depending on the amount of attached gingival tissue available and the depth of the vestibule. ${ }^{8}$

\section{f) Thickness of split thickness flaps raised}

The split thickness pedicle flaps raised for many of the periodontal plastic surgery procedures play an important role in nourishing the grafted tissue. It is essential that this tissue has a certain amount of thickness to be robust enough to fulfil this role. Evidence has shown that flaps with a thickness of less than $1 \mathrm{~mm}$ can negatively affect the outcome in terms of the amount of root coverage achived. ${ }^{9}$

\section{CONTRAINDICATIONS TO PERIODONTAL PLASTIC SURGERY}

\section{a) Smoking}

Any surgical procedure carried out on smokers is likely to have a compromised healing response. Research has shown that smoking can significantly impair the outcome of surgical periodontal therapy when compared to non-smokers. ${ }^{10-13}$ Periodontal plastic surgery should therefore be avoided in patients who smoke.

\section{b) Poor oral hygiene}

Patients with inadequate oral hygiene and active periodontal disease should not be considered for periodontal plastic surgery.

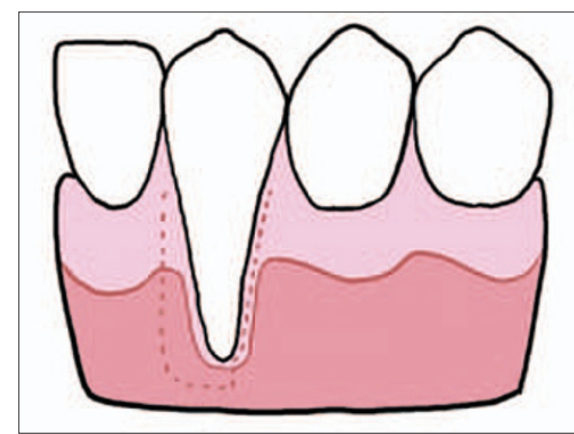

Fig. 1a Diagram showing the outline of the initial incision through the surface epithelium around the recession defect

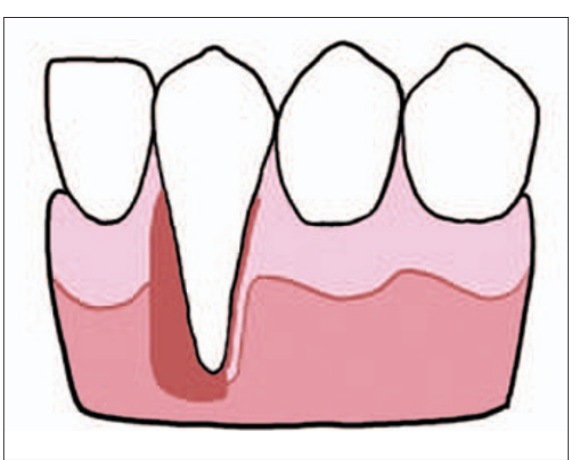

Fig. 1b The surface epithelium is dissected away as shown to leave exposed connective tissue (CT) on the mesial aspect which is now prepared to receive the graft tissue

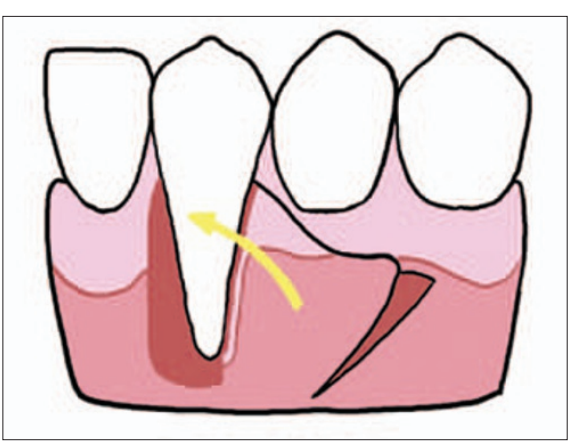

Fig. 1c The amount of tissue required is measured and a split thickness flap is raised on the distal aspect of the root surface. The tissue is laterally repositioned over the recession defect and the exposed $\mathrm{CT}$ on mesial aspect of root

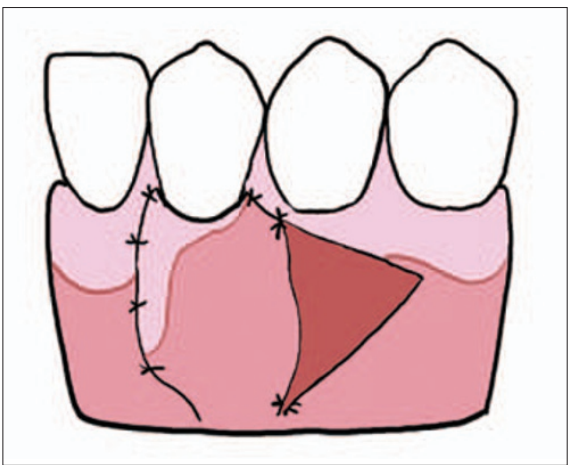

Fig. 1d The pedicle flap is sutured into position and the exposed CT at the donor site is left to heal by secondary intention 


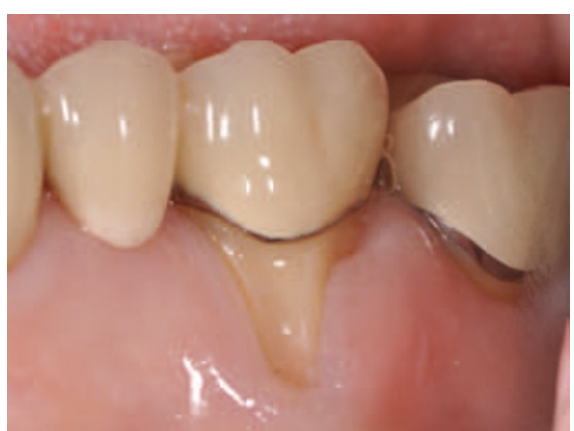

Fig. 1e Pre-op view of a Miller's Class III recession defect on the lower left first molar

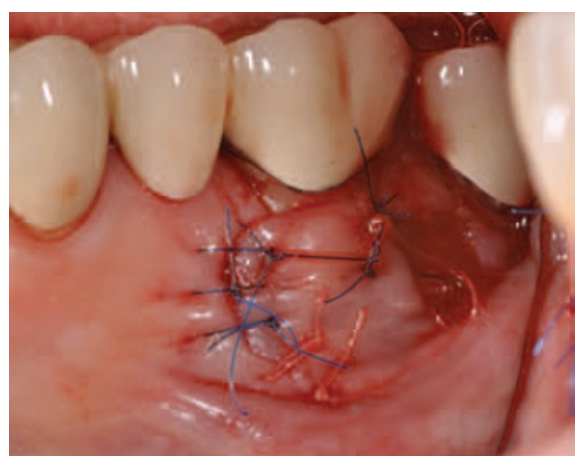

Fig. 1f Surgical site immediately postsurgery with a pedicle flap taken from the mesial aspect of LL7 and repositioned over the recession defect at LL6

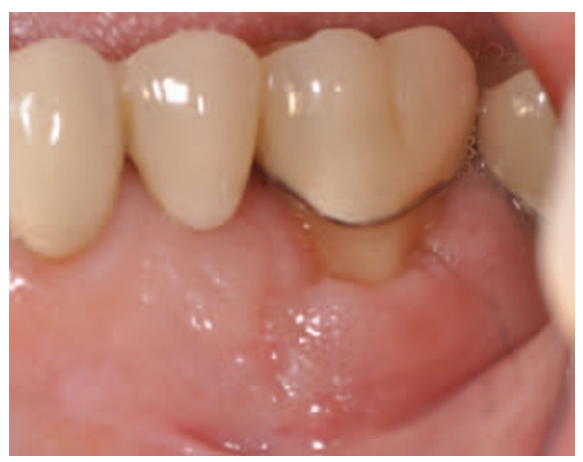

Fig. 1g Clinical appearance one week post surgery

\section{SURGICAL TECHNIQUES FOR CORRECTING RECESSION DEFECTS}

Periodontal plastic surgery is technique sensitive and involves delicate handling of the mucogingival tissues. Burkhardt and Lang $^{14}$ concluded that the use of magnification and microsurgical instruments to handle the tissues resulted in improved vascularisation of connective tissue grafts and increased root coverage compared to macrosurgical techniques.

There are three main types of periodontal plastic surgery procedures described in the literature to treat recession defects. These include pedicle flaps, free grafts, and guided tissue regeneration. ${ }^{15}$ The rest of this article will look at the use of pedicle flaps and a subsequent article in the series will discuss the use of free grafts and guided tissue regeneration.

\section{PEDICLE FLAPS}

A pedicle graft involves repositioning donor tissue from an area adjacent to the recession defect to cover the exposed root surface. It avoids the need of a second surgical site and has the advantage of retaining its own blood supply from the base of the flap which remains attached to the donor site. This helps nourish the graft and facilitates vascular union with the recipient site.

The pedicle flap was first described by Grupe and Warren ${ }^{16}$ as a laterally repositioned full thickness flap. Here the donor tissue is taken from one side of the recession defect and repositioned over the exposed root surface. This was later modified by Hattler ${ }^{17}$ with the use of a split thickness flap repositioned in a similar way to cover multiple exposed root surfaces. Soon after, Cohen and Ross ${ }^{18}$ described the double-papilla repositioned flap for use in areas where there was insufficient keratinised gingival tissue on any one side of the recession defect to reposition and cover the exposed root surface. Here the papillae are taken from both sides of the recession defect and repositioned over the exposed root surface. This procedure limits itself to single tooth recession defects. The doublepapilla flap can also be performed either as a full thickness flap or a split thickness flap depending on the thickness of the gingival tissues. ${ }^{19}$

\section{LATERALLY REPOSITIONED PEDICLE FLAP}

\section{Clinical technique (Figs 1a-g)}

Before raising the donor tissue, the width of the recession defect should be measured to gauge what size pedicle flap is required. To allow adequate union and healing of the repositioned flap a cuff of epithelialised tissue around the margins of the recession defect is cut away to expose the underlying connective tissue. Similarly, the surface epithelium adjacent to the recession defect on the side opposite to where the donor tissue will be taken is also removed to expose the underlying connective tissue (Fig. 1a-b). A pedicle flap twice the width of the recession defect is then raised by making an oblique incision away from the recession defect leaving a few millimetres of keratinised gingival tissue around the adjacent tooth at the donor site. A second oblique distal relieving incision is made towards the apical region from where the first incision terminated and extended beyond the mucogingival junction into the alveolar lining mucosa. A split thickness pedicle flap is then raised and rotated over the exposed root surface and the connective tissue previously exposed on the opposite side (Fig. 1c). The graft tissue should be free from any tension; if not the relieving incision should be extended further apical. Once repositioned the pedicle flap is sutured down with fine interrupted sutures (Fig. 1d) and pressure applied for a few minutes to minimise the clot underneath the pedicle flap. This is important to ensure good union between donor and recipient tissues and to ensure good vascularisation of the grafted tissue. A periodontal dressing can be placed if necessary but is not mandatory. The donor site is left to heal by secondary intention.

If the flap is left under tension, or there is excessive movement and poor stabilisation or if the flap is too narrow for the recession defect, then there is a higher chance of failure of the procedure. Figures 1e-g show an example of a Miller's Class III recession defect on the lower left first molar treated with a laterally repositioned pedicle flap. At one week post-surgery there has been significant coverage of the exposed mesial root surface. Grafting of a Miller's Class III defect of this size is highly unlikely to provide full coverage of the recession defect; however, significant improvement can be made with partial coverage of the root surface and an increased amount of keratinised tissue around the gingival margin as shown in this case. A second surgical procedure with a coronally repositioned flap (discussed later) can be undertaken to try and cover the remaining exposed root surface if necessary.

\section{DOUBLE PAPILLA ROTATIONAL FLAP}

\section{Clinical technique (Figs 2a-b)}

The width of the recession defect should be measured initially to ensure there is sufficient width of tissue available from the two adjacent papillae to allow full coverage of the exposed root surface. A cuff of epithelialised tissue is removed from around the 
recession defect to expose the underlying connective tissue (Fig. 2a). Split thickness flaps of the papillae either side of the recession defect with vertical reliving incisions on the distal line angle of the tooth in front and mesial line angle of the tooth behind should be raised. The relieving incisions are extended beyond the mucogingival line and taken down to bone at this point to help release tension in the flap. The two papillae are repositioned and placed over the exposed root surface and sutured together with fine interrupted sutures along the midline of the exposed root surface (Fig. 2b). A sling suture is placed around the tooth to hold the grafted tissue in its position and prevent it from sliding apically. Gentle pressure is applied for a few minutes to minimise the clot that forms under the pedicle graft and a periodontal dressing can be placed if necessary. The exposed connective tissue at the donor site can be left to heal by secondary intention. Inadequate suturing and inadequate stabalisation can result in separation of the two pedicle flaps resulting in failure of the procedure.

\section{CORONALLY REPOSITIONED FLAP}

\section{Clinical technique (Figs 3a-f)}

The coronally advanced flap was first described by Bernimoulin et al. ${ }^{20}$ The procedure can be performed either as a one

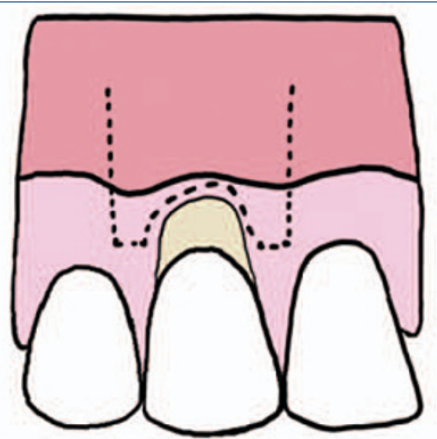

Fig. 3a Diagram outlines the incisions made around the recession defect to raise a split thickness pedicle flap

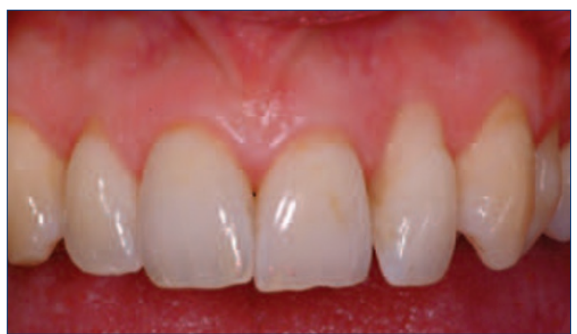

Fig. 3d Pre-op clinical picture showing recession defect at UL2 stage technique to cover shallow recession defects ${ }^{21}$ or a two stage technique which is combined with a free gingival graft, connective tissue graft or with guided tissue regeneration procedures. If the gingival tissue apical to the recession defect has thin gingival biotype or there is insufficient keratinised tissue, a free gingival graft or a connective tissue graft can be carried out first to increase the thickness and amount of keratinised tissue. After approximately three months of healing the tissue can be coronally repositioned as a second stage surgery. If the gingival biotype is thick and there is adequate keratinised tissue (minimum $3 \mathrm{~mm}$ ) then the tissue can be coronally repositioned as a one-stage technique. In order to carry out this procedure it is essential to ensure there are shallow crevicular depths on interproximal surfaces and no interproximal bone loss. ${ }^{1}$

The amount of coronal advancement required is determined by measuring the height of the recession defect. The same length is then measured from the tip of the papilla towards the apex and horizontal incisions are placed through the tissue for a split thickness flap. Vertical relieving incisions are placed at the distal line angle of one tooth anteriorly and mesial line angle of one tooth posterior to the tooth with the recession defect (Fig. 3a). A split

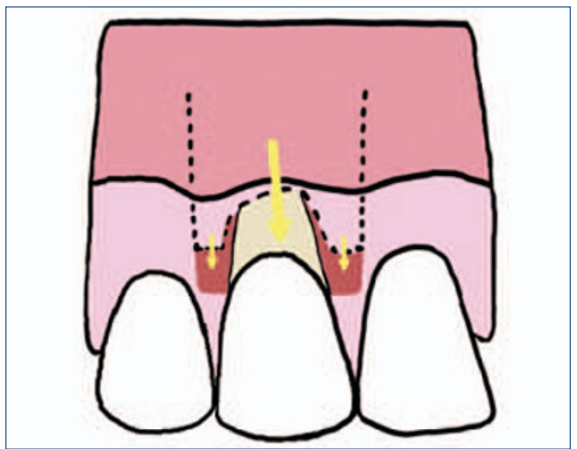

Fig. $3 b$ The surface epithelium coronal to the pedicle flap is removed to expose the underlying connective tissue. This prepares the site to receive the graft tissue

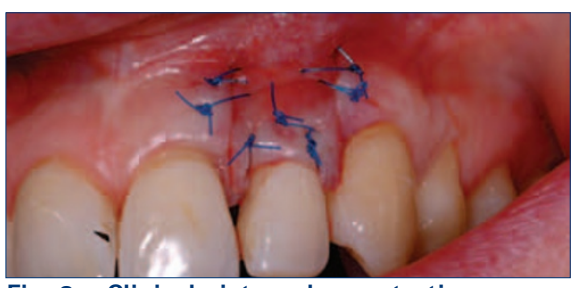

Fig. 3e Clinical picture demonstrating a coronally advanced pedicle flap sutured in position over the recession defect

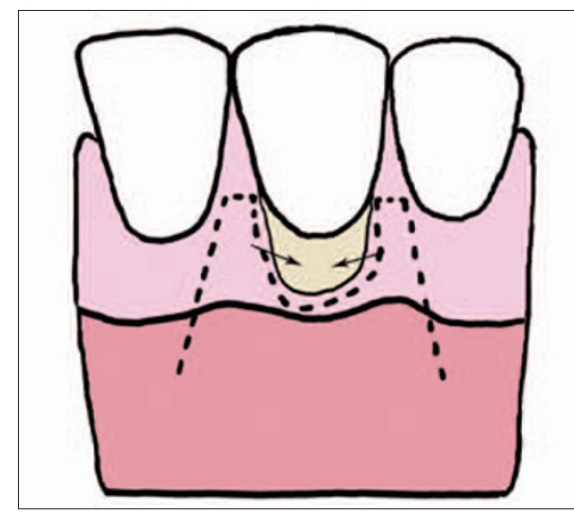

Fig. 2a Outline of the incisions made over the papilla either side of the recession defect to raise a split thickness pedicle flap

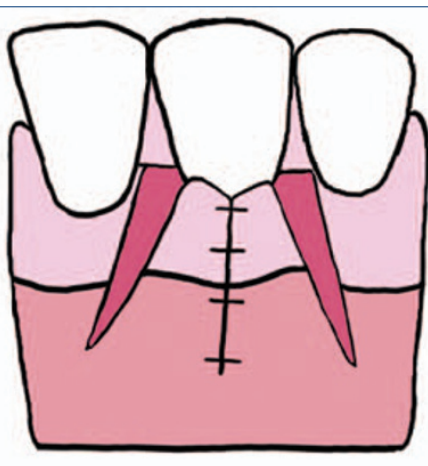

Fig. $2 \mathrm{~b}$ The pedicle flaps are sutured together over the recession defect.

thickness flap of even thickness is raised and extended beyond the mucogingival margin. The periosteum is released to allow freedom of movement of the flap. The most coronal part of the papilla which remains

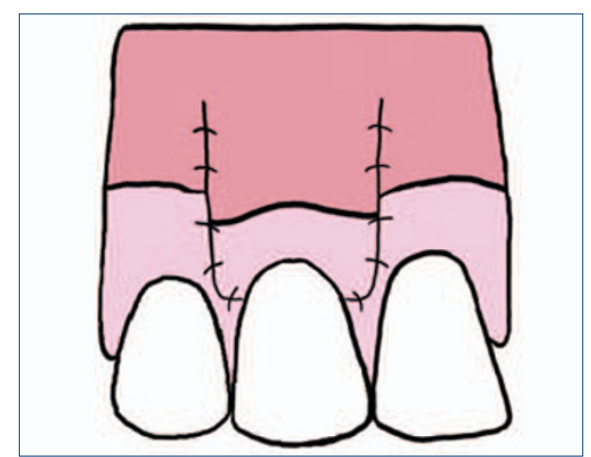

Fig. 3c Diagram shows the pedicle flap coronally repositioned and sutured over the recession defect

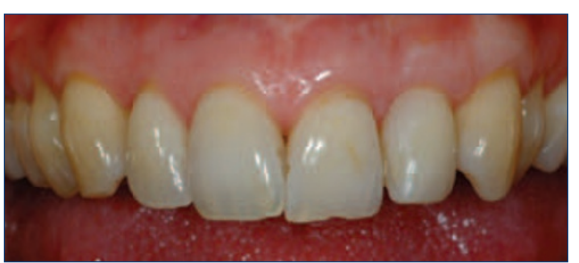

Fig. 3f Post op clinical view of UL2 following grafting over recession defect, minor enameloplasty to reduce length of tooth and some minor addition of composite mesially to improve overall shape of the tooth 
intact is de-epithelialised before coronal advancement of the flap (Fig. 3b). The flap is then sutured in place approximately $0.5 \mathrm{~mm}$ to $1 \mathrm{~mm}$ coronal to the $\mathrm{CEJ}^{22}$ with interrupted sutures in the papilla regions and along the reliving incisions (Fig. 3c). Gentle pressure is applied for a few minutes and if necessary a periodontal dressing can be placed. Excessive tension in the coronally advanced flap can result in failure or a reduced amount of root coverage. Figures $3 d-f$ show an example of a recession defect at UL2 treated initially with a connective tissue graft (see article 3) to increase the thickness of the gingival tissues around the recession defect followed by a second surgical procedure with a coronally repositioned pedicle flap to cover the recession defect. The tooth has also had some minor enameloplasty to decrease the length and some composite bonding to improve the overall shape of the tooth.

\section{PROGNOSIS}

Periodontal plastic surgery has been shown to be effective in reducing gingival recession defects with a concomitant improvement in attachment levels. ${ }^{23}$ Achieving full root coverage following a single periodontal plastic surgical procedure is difficult and success is often considered to be any decrease in amount of exposed root surface (Fig. 1g) ie an increase in gingival height from the mucogingival line to the gingival margin. ${ }^{24}$ The size of the initial recession defect will also influence the final outcome. A recent systematic review found that overall a better percentage of complete and mean root coverage was seen in recession defects less that $4 \mathrm{~mm}$.

The mean root coverage achieved with a laterally repositioned flap and the double papilla flap have shown to vary between $34-81 \%$ and complete root coverage varies between $40-50 \%$ of sites. ${ }^{25,26}$ With these procedures there is a risk of donor site recession particularly with the laterally repositioned flap of approximately $1 \mathrm{~mm} .{ }^{27}$ The mean root coverage achieved with a single stage coronally repositioned flap varies between 55-99\% and complete root coverage ranges from 24-95\% of sites. ${ }^{25,26}$ Pini-Patro et al. ${ }^{28}$ concluded that in order to achieve $100 \%$ root coverage with a coronally repositioned flap, the flap should be over compensated by 2-2.5 mm and sutured tension free. However, this may be difficult in cases where there is a large recession defect and a shallow sulcus depth. The coronally advanced flap is often used together with a subepithelial connective tissue graft and has proven to be the gold standard treatment in the treatment of recession defects. ${ }^{29}$ In Miller's Class I defects this combination has shown to provide complete root coverage of the recession defect. ${ }^{30}$ The use of connective tissue grafts is discussed further in the third article in this series.

\section{CONCLUSIONS}

Pedicle flaps can be useful in correcting small Miller's Class I and II recession defects. The graft has the advantage of retaining its own blood supply which can aid healing; however, this graft should be restricted to cases where the gingival biotype is thick and there is sufficient amount of keratinised tissue adjacent to the recession defect. In cases with thin gingival biotype or limited keratinised tissue it may be more sensible to consider a free graft, possibly in combination with a pedicle graft.

The authors would like to thank Dr Paul Baker, Specialist Periodontist for contributing the clinical pictures shown in Figures 1e-1g.

1. Kassab M M, Cohen R E. Treatment of gingival recession. J Am Dent Assoc 2002; 133: 1499-1506.

2. Saha $S$, Bateman G J. Mucogingival grafting procedures - an update. Dent Update 2008; 35: 561-562, 565-568

3. Miller P D, Jr. A classification of marginal tissue recession. Int J Periodontics Restorative Dent 1985; 5: 8-13.

4. Lindhe J, Nyman S. Long-term maintenance of patients treated for advanced periodontal disease. J Clin Periodontol 1984; 11: 504-514.

5. Lindhe J, Westfelt E, Nyman S, Socransky S S, Haffajee A D. Long-term effect of surgical/nonsurgical treatment of periodontal disease. J Clin Periodontol 1984; 11: 448-458.

6. Miller P D, Jr. Root coverage using the free soft tissue autograft following citric acid application. III. A successful and predictable procedure in areas of deep-wide recession. Int J Periodontics Restorative Dent 1985; 5: 14-37.

7. Polson A M, Frederick G T, Ladenheim S, Hanes P J. The production of a root surface smear layer by instrumentation and its removal by citric acid. J Periodontol 1984; 55: 443-446.

8. Baker P. The management of gingival recession. Dent Update 2002; 29: 114-120, 122-124, 126.

9. Chambrone L, Sukekava F, Araújo M G, Pustiglioni $F E$, Chambrone L A, Lima L A. Root-coverage procedures for the treatment of localized recession-type defects: a Cochrane systematic review. J Periodontol 2010; 81: 452-478.
10. Preber $H$, Bergstrom J. Effect of cigarette smoking on periodontal healing following surgical therapy. J Clin Periodontol 1990; 17: 324-328.

11. Trombelli L, Scabbia A. Healing response of gingival recession defects following guided tissue regeneration procedures in smokers and non-smokers. $J$ Clin Periodontol 1997; 24: 529-533.

12. Martins A G, Andia D C, Sallum A W, Sallum E A, Casati M Z, Nociti Júnior F H. Smoking may affect root coverage outcome: a prospective clinical study in humans. J Periodonto/ 2004; 75: 586-591.

13. Chambrone L, Chambrone D, Pustiglioni FE, Chambrone $L A$, Lima $L A$. The influence of tobacco smoking on the outcomes achieved by root-coverage procedures: a systematic review. J Am Dent Assoc 2009; 140: 294-306.

14. Burkhardt $R$, Lang N P. Coverage of localized gingival recessions: comparison of micro- and macrosurgical techniques. J Clin Periodontol 2005; 32: 287-293.

15. Chambrone L, Sukekava F, Araújo M G, Pustiglioni $F E$, Chambrone L A, Lima L A. Root coverage procedures for the treatment of localised recession-type defects. Cochrane Database Syst Rev 2009; (2): CD007161.

16. Grupe HE, Warren R F. Repair of gingival defects by a sliding flap operation. J Periodonto/ 1956; 27: 92-95.

17. Hattler A B. Mucogingival surgery - utilization of interdental gingiva as attached gingiva by surgical displacement. Periodontics 1967; 5: 126-131.

18. Cohen D W, Ross S E. The double papillae repositioned flap in periodontal therapy. J Periodontol 1968; 39: 65-70.

19. Pfeifer J S, Heller R. Histologic evaluation of full and partial thickness lateral repositioned flaps: a pilot study. J Periodontol 1971; 42: 331-333.

20. Bernimoulin J P, Luscher B, Muhlemann H R. Coronally repositioned periodontal flap. Clinical evaluation after one year. J Clin Periodonto/ 1975; 2: 1-13.

21. Allen E P, Miller P D, Jr. Coronal positioning of existing gingiva: short term results in the treatment of shallow marginal tissue recession. J Periodontol 1989; 60: 316-319.

22. Maynard J G, Jr. Coronal positioning of a previously placed autogenous gingival graft. J Periodontol 1977; 48: 151-155.

23. Roccuzzo M, Bunino M, Needleman I, Sanz M. Periodontal plastic surgery for treatment of localized gingival recessions: a systematic review. J Clin Periodontol 2002; 29(Suppl 3): 178-194.

24. Wennström J L, Zucchelli G. Increased gingival dimensions. A significant factor for successful outcome of root coverage procedures? A 2-year prospective clinical study. J Clin Periodontol 1996; 23: 770-777.

25. Wennström J L. Mucogingival therapy. Ann Periodontol 1996; 1: 671-701.

26. Pagliaro U, Nieri M, Franceschi D, Clauser C, PiniPrato G. Evidence based mucogingival therapy. Part 1: A critical review of the literature on root coverage procedures. J Periodonto/ 2003; 74: 709-740.

27. Caffesse R G, Guinard E A. Treatment of localized gingival recessions. Part IV. Results after three years. J Periodontol 1980; 51: 167-170.

28. Pini Prato G P, Baldi C, Nieri M et al. Coronally advanced flap: the postsurgical position of the gingival margin is an important factor for achieving complete root coverage. J Periodonto/ 2005; 76: 713-722.

29. Chambrone L, Faggion C M, Jr, Pannuti C M, Chambrone L A. Evidence based periodontal plastic surgery: an assessment of quality of systematic reviews in the treatment of recession-type defects. J Clin Periodontol 2010; 37: 1110-1118.

30. Cairo F, Pagliaro U, Nieri M. Treatment of gingival recession with coronally advanced flap procedures: a systematic review. J Clin Periodontol 2008. 35(8 Suppl): 136-162. 